\title{
Moment JOURNAL
}

Journal of Cultural Studies, Faculty of Communication, Hacettepe University 2019, 6(2): 545-551

ISSN: 2148-970X.

Interview

\section{INTERVIEW WITH PAOLO GERBAUDO ON DIGITAL PARTIES: THE ERA OF HYPER LEADERS AND START- UP PARTIES}

\section{Sarphan Uzunoğlu*}

The legitimacy of traditional media and political institutions has been the subject of debate for a long time. We observe that the confidence in traditional actors is diminished in public opinion polls and the reasons of major problems of societies are linked to these actors. Especially after 2008 crisis, delegitimitisation of political parties, media and governmental institutions accelerated the change in the political sphere and triggered the birth of new political formations in various countries. Dr. Paolo Gerbaudo, Director of the Centre for Digital Culture at King's College London, is one of the scholars who have been working on the formations of these emerging political movements. His new book The Digital Party: Political Organisation and Online Democracy (2019) focuses on the transformation of political parties in the time of Facebook. We have talked about the nature of these emerging political formations, their potential contributions to democracy and what are the similarities between these political parties and new generation technology companies such as Uber and Airbnb.The legitimacy of traditional media and political institutions has been the subject of debate for a long time. We observe

\footnotetext{
* Assistant Professor of Multimedia Journalism in Lebanese American University. ORCID ID: 0000-0002-9736-1763, sarphan.uzunoglu@lau.edu.lb Date of the Interview: Via E-mail, on 17 June 2019, Via E-mail, on 16 September 2019.

(C) Author(s) (or their employer(s)) 2019. Re-use permitted under CC BY-NC 4.0. No commercial re-use. See open access policy. Published by Faculty of Communication, Hacettepe University
} 
that the confidence in traditional actors is diminished in public opinion polls and the reasons of major problems of societies are linked to these actors. Especially after 2008 crisis, delegitimitisation of political parties, media and governmental institutions accelerated the change in the political sphere and triggered the birth of new political formations in various countries. Dr. Paolo Gerbaudo, Director of the Centre for Digital Culture at King's College London, is one of the scholars who have been working on the formations of these emerging political movements. His new book The Digital Party: Political Organisation and Online Democracy (2019) focuses on the transformation of political parties in the time of Facebook. We have talked about the nature of these emerging political formations, their potential contributions to democracy and what are the similarities between these political parties and new generation technology companies like Uber and Airbnb.

You mention that the digital party is the translation of the business model and organisational innovation of digital corporations to the political arena and their application to the idealistic project of the construction of a new democracy in digital times. Do you think this convergence would pose a threat to the nature of democracy in the future? Why or why not?

The translation of the business model to political parties obviously raises serious dangers and risks. However, we need to take into account that in a way this has already happened in the past. The Taylorist model of company was partly translated to mass parties, in the integrated structure which they constructed. The problem mainly lies in the way in which some parties are literally becoming companies. For example, the Brexit party of Farage is registered as a private limited company (PLC). This means that no democracy can be seriously enacted in this form.

What are the possible risks of adapting the management models of this social platforms to political parties? What are the possible outcomes of political parties' conversion into companies?

The risks are manifold. On the one hand, there is the evident risk posed by new forms of management and manipulation that are inherent to the use of digital platforms. The organisational use of digital platforms means that our data is controlled by party personnel and can be used for purposes of internal surveillance and profiling to repress internal dissent. On the other hand there is a more general risk of turning the parties 
into firm parties, constantly aiming to improve their performance in response to user metrics thus leading to opportunism at the expense of their ideological coherence.

Your work is based on the analysis of emerging political models in Europe. Taking digital division in some other regions of the world into consideration, do you think that these models can be applied to, for instance, a country in the Middle East?

I think that these models will be applied and in fact are partly already being applied around the world. Because despite our difference in culture and geography it is evident that we share the same technological apparatus and the same mode of production and this carries in tow the same mode of organisation. There are already signs that organisations in other countries have integrated social media platforms deeply in their functioning and we are bound to see this happening more and more.

What are the basic differences between Pirate Parties and parties you have observed in your work? Do you think that, Pirate Parties lack any of the characteristics of a digital party you listed as cloud party, start-up party?

Pirate Parties were the first to experiment with this model of organisation and democracy. But in a way, they have remained quite small parties. This was mostly down to the fact that they have a highly participatory definition of direct democracy that it is very difficult to scale up in any meaningful way. They certainly have been start-up parties given their rate of growth and cloud party, because alike other digital parties they do not have offices.

Could you specify the differences between pirate parties and these new parties you focused on which shows certain corporate characteristics?

Pirate parties are part of the first wave of digital parties. They were more idealistic in character and were also smaller in size. Their abided by a strictly libertarian ethos that aimed at turning parties into fully participatory systems. This effort has not been very successful though as some of these parties have been marred by internal strife. However, these parties constituted an important inspiration for other and larger parties as Podemos, the 5 Star, etc.

Digital parties you observed seem to benefit from the heritage of traditional parties a lot. In one of the chapters you said that digital parties eliminated these traditional 
actors through eliminating local branches in their decision making processes. Do you think that it has affected individuals' participation to politics positively?

By eliminating the intermediate layers of political parties, digital parties, in a way, do something that has already happened in companies with the neo-management described by Boltanski and Chiappello. They try to transform themselves into platforms like Airbnb and Uber.

Could you please describe what are the characteristics of these parties that resemble Airbnb and Uber and in which ways these characteristics positively or negatively effect regarding parties?

The main element of similarity with consumption apps as Airbnb and Uber is the fact that there is disintermediation in the way in which services are delivered. Airbnb have eroded the role played by intermediaries such as travel agencies, local cab companies, or hotels. Digital parties are in a way doing the same with political organisation, doing away with intermediary party organisers such as cadres and functionaries that played a fundamental connecting role between the base and the summit of the party. Yet, in both cases disintermediation goes hand in hand with a new form of intermediation, a reintermediation that creates new centres of power.

You mention a controversial term named hyper-leadership, which you define as the new type of leader that stands at the forefront of digital parties. Do you think that this new form of leadership seems to be conflicting with decentralized decision making mechanisms with direct participation?

No that is the paradox. Decentralization of direct participation goes hand in hand with centralization at the top. This is something people often overlook when thinking about the internet in general. Dispersal of access has been accompanied by greater functional integration and centralization. Think about Facebook: We all use it in a dispersed space but it is centralized by Facebook as an interface and algorithm. The hyper-leader acts as a central functional node which centralises our interactions in a rather similar way.

What are the factors lying behind the birth of this hyper-leadership concept?

It stems from the power of celebrities in the social media era. We are in an even more celebrity-obsessed world than we were in the era of TV. Social media have become a space where celebrities supposedly present themselves in a more authentic manner. We 
all know this is all stage, but still that is the narrative. Hyper-leaders are social media celebrities and political leaders at the same time. Or better, they are political leaders because they are social media celebrities.

Do you think that these digital parties have the potential of turning into plebiscitarian dictatorships of the future?

Digital parties can turn into plebiscitarian and dictatorial formations. Partly they are already becoming that. However, that is not necessarily their end. They can also serve to democratise politics by allowing people to participate more in the political process.

What are the possible actions political parties might take to fight against turning into plebiscitarian formations? Is it possible in their existing structures or in the existing structure of uses of the internet and the nature of collective digital actions?

On the one hand some form of plebiscitarianism is not negative per se, as referendums have been used for a long time also within organisations as trade unions and left parties. However, there is indeed a risk that it may lead to undemocratic and autocratic forms of party management. To guard against it the best measure is to introduce forms of extended discussion within political parties, ensuring that people participate actively, and are able to shape decisions not only quantitatively (by voting), but also qualitatively by putting forward policy proposals and amendments.

You also mention that the organizational restructuring is not causing a radical diffusion of power in organisations, nor does it lead to a situation in which 'everyone is of equal worth'. What are the possible factors that prevent digital parties from making radically inclusive participatory democracy possible?

The fact is that an equal participation is impossible as such. Post-68 participatory cultures have given us the illusion that this is possible. But this is just a narcissistic and individualistic "look at me" culture. The reality is that in organisations there is always power and that it is always unevenly distributed. Therefore, the question is not to diffuse it but to control it.

You state that registering to these parties' platforms as a member, is often as easy as signing up for social media such as Facebook, thus significantly lowering barriers to participation. Does this guarantee high level of engagement? Because, many recent 
studies about social networks reveal that, there are users who are named as super users and known to be more active than majority of users in many social networks? The same applies to these parties. While it is very easy to become a member this does not translate into equality of participation. To the contrary there is a very small number of users that concentrate almost all of the participation. Perhaps a $1 \%$ of users, with another $9 \%$ participating slightly and a $90 \%$ just lurking.

Considering that all decision making systems have their own biases, and they might be used for in-party surveillance; do you think that platforms which are developed for decision making mechanisms may turn into in-party control/surveillance tools? They can turn into surveillance tools of the leadership on the base. Obviously they may also be hacked by state actors and used to get the membership list of parties and look into the membership details.

In the conclusion chapter of your book, it is stated that "The rise of new political parties reflects a new cleavage in society, stemming from technological and economic factors: Fracture between political and/or economic insiders and what I call connected outsiders." Do you think that precarious working relations these people have experienced, triggered more outsiders' interest in political decision making processes?

Yes, because more precarious working relations mean people cannot go to meetings that easily, and as a consequence they are more likely to be attracted to forms of participation that do not require physical presence.

What kind of potential all these new parties have in terms of enforcing participation in the countries they have emerged in? Do you think they really enforce democracy? Especially considering daily working routines, is it possible for these parties to make people more integrated to daily decision making mechanisms?

I think that they have had a positive effect in terms of involving people who did not engage with politics before. Furthermore, they have experimented with new practices and mechanisms that try to innovate the way decision-making is conducted. Finally, they have allowed people who because of family or work commitments cannot participate physically to have a way to participate in decisions at a distance. This said, the practical realisation has often been disappointing and the promise of a truly member-led democracy has not been completely fulfilled. 
Do you think digital parties might be solution to secterian political cultures? Can they be understood as unifying political actors?

They may be partly, because they can contribute in widening participation, and the wider a party is the less likely it is to be sectarian. However, as in all things political technology alone does not offer a solution. The solution is always political. 